\title{
Alluvial visualization and computation of probabilities of transitions in frailty index states over an 8-year period using multi-state Markov models
}

\author{
Roman Romero-Ortuno \\ The Irish Longitudinal Study on \\ Ageing (TILDA), \\ Trinity College Dublin, \\ Dublin, Ireland \\ ORCID: 0000-0002-3882-7447 \\ Rose Anne Kenny \\ The Irish Longitudinal Study on \\ Ageing (TILDA), \\ Trinity College Dublin, \\ Dublin, Ireland \\ ORCID: 0000-0002-9336-8124
}

\author{
Peter Hartley \\ Department of Public Health and \\ Primary Care, \\ University of Cambridge, \\ Cambridge, UK \\ ORCID: 0000-0002-1033-5897 \\ Aisling M. O’Halloran \\ The Irish Longitudinal Study on \\ Ageing (TILDA), \\ Trinity College Dublin, \\ Dublin, Ireland \\ ORCID: 0000-0001-5498-4453
}

\author{
Silvin P. Knight \\ The Irish Longitudinal Study on \\ Ageing (TILDA), \\ Trinity College Dublin, \\ Dublin, Ireland \\ ORCID: 0000-0003-1245-4870
}

\begin{abstract}
The Frailty Index (FI) is an operationalization of frailty in older adults based on the accumulation of health deficits. FI cut-offs define the non-frail, prefrail and frail states. We described longitudinal transitions of FI states in The Irish Longitudinal Study on Ageing (TILDA). We included participants with information for a 31-deficit FI at TILDA wave 1 (2010), and follow-up over four subsequent longitudinal waves (2012, 2014, 2016, 2018). Next-wave transition probabilities were estimated using multi-state Markov models, and we investigated the effects of age, sex and education. 8174 wave 1 participants were included (54.2\% female; mean age 63.8 years). Probabilities from non-frail to prefrail, and non-frail to frail were $18 \%$ and $2 \%$, respectively. Prefrail had $19 \%$ probability of reversal to non-frail, and $15 \%$ risk of progression to frail. Frail had $21 \%$ probability of reversal to prefrail and $14 \%$ risk of death. Being older and female increased the risk of adverse FI state transitions, but being female reduced the risk of transition from frail to death. Higher level of education was associated with improvement from prefrail to non-frail. FI states are characterized by dynamic longitudinal transitions. Alluvial plots and Markov Models can help appreciate these dynamic state transitions in big data.
\end{abstract}

Keywords - Aged, Frailty, Longitudinal, Surveys, Transition

\section{INTRODUCTION}

As populations get older, the association between chronological age and health status becomes increasingly variable, to the extent that for a large sector of the older population, chronological age is not a relevant marker for understanding the experience of ageing [1]. To describe this heterogeneity in health status as we age, the concepts of biological age [2], or frailty versus fitness spectrum [3] have been proposed.

The Frailty Index (FI) methodology was introduced by Rockwood and colleagues $[4,5]$ as a way to quantify the accumulation of people's health 'deficits' (i.e. symptoms,

This study was funded by a Grant from Science Foundation Ireland under Grant number 18/FRL/6188. TILDA is funded by Atlantic Philanthropies, the Irish Department of Health and Irish Life. The funders had no role in the conduct of the research and/or preparation of the article; in study design; in the collection, analysis and interpretation of data; in writing of the report; or in the decision to submit the paper for publication. clinical signs, medical conditions and disabilities) at a given chronological age. As per published standard procedure [6], a FI can be constructed on any suitable health database by considering a minimum of 30 deficits that need to satisfy the following criteria: (a) be associated with health status, and not simply attributes (e.g. hear graying); (b) cover a range of systems; (c) not saturate too early (e.g. presbyopia is nearly universal by age 55); and (d) their prevalence must increase with age (excluding survivor effects); in addition, in repeated assessments the FI construction must be the same [6].

Since FI deficits must increase with age, the FI has a statistically significant association with chronological age [7]. However, on account of the above-mentioned population heterogeneity, the effect size of this association has been found to be small $[8,9]$. The sex-specific properties of the FI have also been studied. A systematic review and metaanalysis consistently showed that women have higher FI scores than males at all ages [10]. However, whilst women tend to accumulate more deficits than men of the same age, their risk of mortality tends to be lower [4]. Socioeconomic status, including education, has also been reported to explain variation in FI within individuals of the same chronological age [11].

Frailty in older adults can be improved and even reversed with appropriate medical and non-medical interventions [12]. However, clinicians and the public often believe that frailty is a 'fixed' state with little potential to change over time. There is a need to help clinicians and the public understand the dynamic nature of frailty over time. With this audience in mind, our aim was to describe the 8-year longitudinal transitions of FI states using big data from a longitudinal study of ageing.

\section{METHODS}

\section{A. Design and Setting}

We analyzed data from a population-based longitudinal study that collects information on the health, economic and social circumstances from people aged 50 and over in Ireland (The Irish Longitudinal Study on Ageing: TILDA). Wave 1 of the study (baseline) took place between October 2009 and February 2011, and subsequent data was collected approximately 2-yearly over four longitudinal waves (wave 2: 


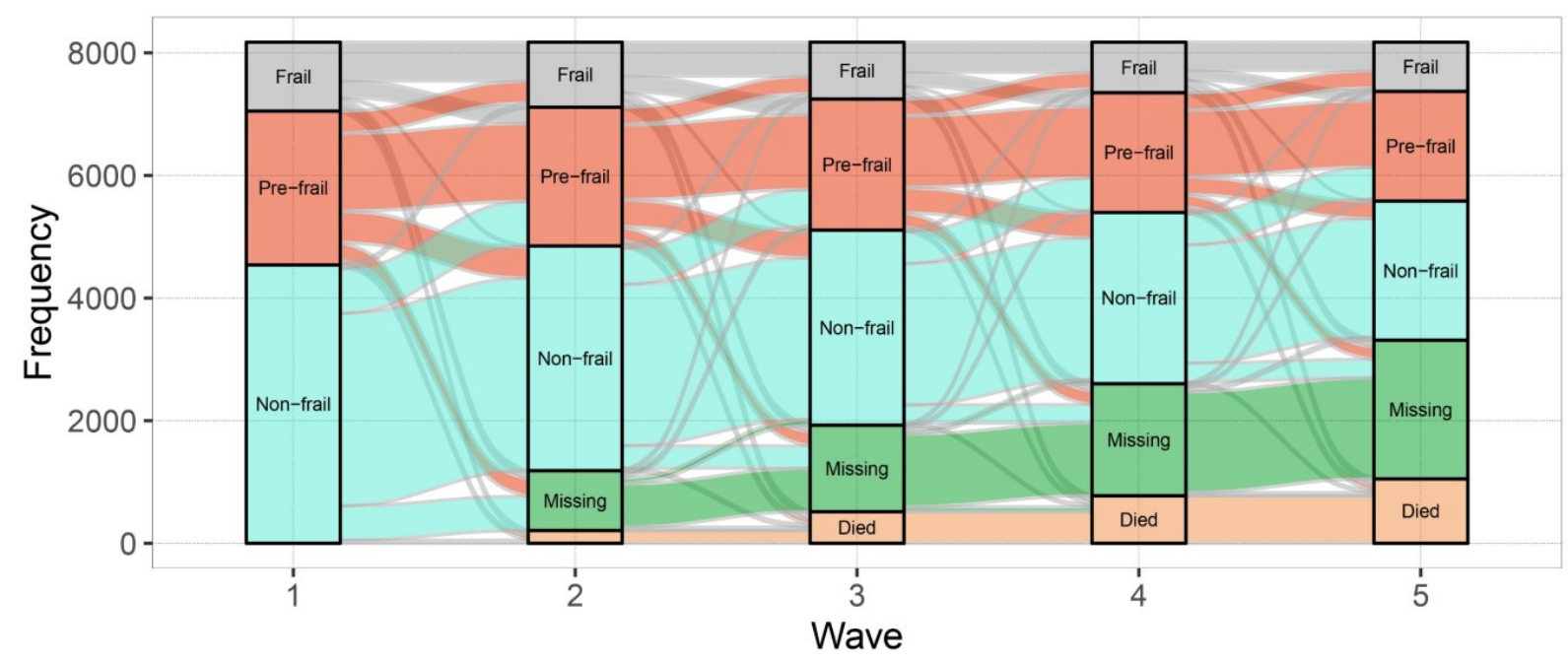

Fig. 1. Alluvial chart of the longitudinal transitions of FI states in TILDA.

February 2012 to March 2013; wave 3: March 2014 to October 2015; wave 4: January to December 2016; wave 5: January to December 2018). An overview of the study is available on https://tilda.tcd.ie/about/where-are-we-now/. The full cohort profile has been described elsewhere [13, 14]. Ethical approval for each wave was obtained from the Faculty of Health Sciences Research Ethics Committee at Trinity College Dublin, Ireland. All participants provided written informed consent prior to inclusion in the study.

\section{B. Sample}

The baseline analytical sample included participants who had complete FI information at Wave 1. For subsequent waves, information was collected on transitions in FI states and attrition due to deaths or missing data. Age, sex and highest educational attainment were also recorded at baseline (wave 1).

\section{Construction of the Frailty Index (FI)}

As previously published [15], a 31-item FI was constructed using self-reported health measures available in TILDA's Computer-Assisted Personal Interview (CAPI) questionnaire conducted at wave 1 . The selection of deficits was consistent with the standard FI requirements [6], including that deficits are any symptom, sign, disease or disability associated with age and adverse outcomes, are present in at least $1 \%$ of the population, cover several organ systems, and have under 5\% missing data [15]. The components of this 31-item FI are given in Appendix I. Deficits with more than two categories (i.e. no $=0$ or yes $=1$ ) were coded as a proportion of the number and order of responses; for example, five answer categories for the deficit 'Self-rated physical health': Excellent, Very good and Good were coded as 0 (no deficit); Fair was coded as 0.5 (partial deficit); and Poor was coded as 1.0 (full deficit). Analyses from diverse datasets have suggested that variables included in an FI can be coded either as dichotomous or ordinal, with negligible impact on the performance of the index in predicting mortality [16]. In keeping with previous literature [17], the following cut-offs were applied at each wave for the definition of the three FI states: FI $<0.10$ : non-frail; FI $\geq 0.25$ : frail; rest: prefrail.

\section{Mortality}

Mortality was ascertained for all study participants at each follow-up wave. TILDA has approval from Ireland's Central Statistics Office to link survey respondents to their death certificate information held centrally by the General Register Office, where every death in the Republic of Ireland must be registered [18]. Other than deaths, attrition at each wave was classified as 'missing'.

\section{E. Statistical Analysis}

Descriptive statistics were computed with IBM SPSS Statistics version 25 (IBM Corp., Armonk, NY, USA) and given as mean with standard deviation (SD) and range or proportion (\%).

For the visualization of the longitudinal trajectories of the three FI states, an alluvial chart was created using the $\mathrm{R}$ ggalluvial package [19]. In the alluvial plot, the height of the stacked bars at each wave (which represent whether participants' status for the given frailty state was yes, no, missing or died) is proportional to the number of participants identified as belonging to this state at each wave. The thickness of the streams connecting the stacked bars between waves are proportional to the number of participants who have the state identified by both ends of the stream.

To estimate transition probabilities for the FI states, we used multi-state Markov models using the $\mathrm{R}$ msm package, which allows a general multi-state model to be fitted to longitudinal data [20]. The multi-state Markov model is a way of describing a process in which individuals move through a series of states over time. All missing data were censored and considered missing completely at random. In addition, we conducted sensitivity analyses where missing data was modelled as an additional state in the models. We obtained matrices of estimated transition probabilities from wave $\mathrm{x}$ to wave $\mathrm{x}+1$ (with $95 \%$ confidence intervals [CIs]) for each FI state. We adjusted the multi-state Markov models for age, sex and education. Multi-state Markov models handle confounders at baseline and subsequent waves. Whilst sex and education remained constant across waves, the age covariate was time-varying (i.e. increased for each wave); if participants missed a wave, age was imputed by adding 2 years from the preceding wave. Hazard ratios (HRs) and 95\% CIs for the estimated covariate effects of age, sex and education were 


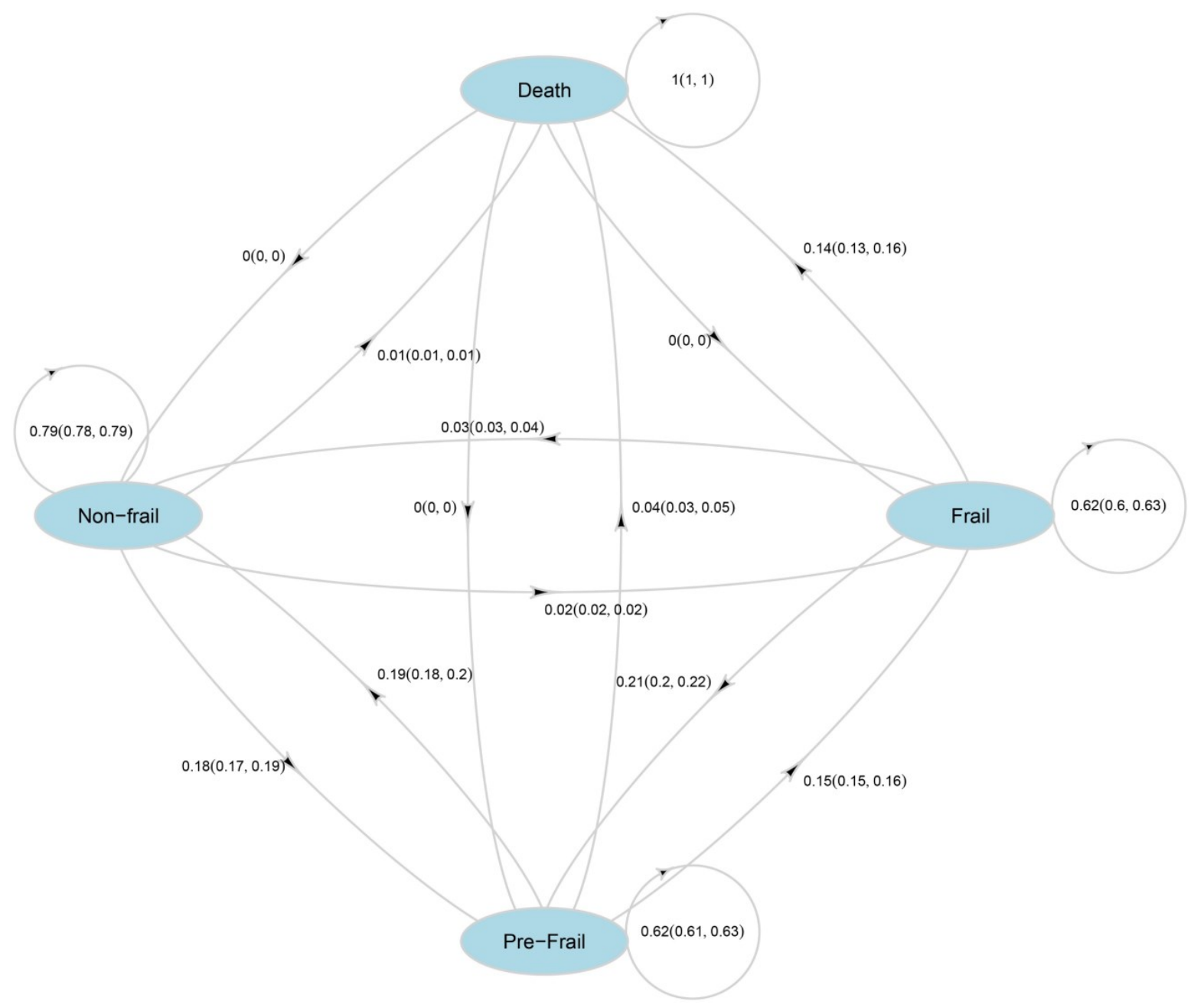

Fig. 2. Estimated transition probability (and $95 \% \mathrm{CIs}$ ) for each frailty index state (from wave $\mathrm{x}$ to wave $\mathrm{x}+1$ ).

obtained. HRs were considered significant when their CIs did not include 1 .

\section{RESULTS}

TILDA wave 1 recruited a total of 8504 participants, of whom $330(3.9 \%)$ were aged less than 50 years. The remaining 8174 had complete FI information (3744 men and 4430 women). The mean (SD; minimum-maximum) age of wave 1 participants $(\mathrm{n}=8174)$ was $63.8(9.8 ; 50-105)$ years; for wave $2(\mathrm{n}=6994): 65.5(9.5 ; 52-97)$; for wave $3(\mathrm{n}=6249): 67.5$ $(9.2 ; 54-98)$; for wave $4(\mathrm{n}=5571): 69.2(8.9 ; 56-101)$; and for wave $5(\mathrm{n}=4874)$ : $70.6(8.5 ; 58-103)$. The counts and proportions for FI states and deaths at each wave is presented in Table I. The alluvial plot is shown in Fig. 1 and transition numbers are detailed in Appendix II (Table III). As expected, the cumulative proportions of deaths and missing data increased across waves.

Probabilities from non-frail to prefrail, and non-frail to frail were $18 \%$ and $2 \%$, respectively. Prefrail had a $19 \%$ probability of reversal to non-frail, and a $15 \%$ risk of progression to frail. Frail had a 3\% probability of reversal to non-frail, a $21 \%$ probability of reversal to prefrail, and a $14 \%$ risk of death. Risks of death for non-frail and prefrail states were low (1\% and 4\%, respectively). Fig. 2 visually shows the transition probabilities, with $95 \%$ CIs.
Appendix III (Table IV) shows a sensitivity analysis of the same multi-state Markov models where missing data was modelled as an additional state. As regards FI states, the probability of remaining missing was $82 \%$, and there was an $11 \%$ probability for transitioning to missing from either the non-frail, prefrail or frail state.

Table II provides the HRs and 95\% CIs of the estimated covariate effects of sex, age and education (secondary and third level compared to primary or less) in the multi-state Markov models. Being older increased the risk of adverse state transitions from frail to death, from prefrail to frail, from non-frail to prefrail, and from non-frail to death. The opposite was suggested for favourable transitions from frail to prefrail, and prefrail to non-frail.

With regards sex, being female increased the risk of adverse transitions from non-frail to prefrail, and prefrail to frail; however, it reduced the risk of transition from frail to death. Being female reduced the risk of favorable transitions from pre-frail to non-frail and frail to prefrail. In terms of education, there were trends in the expected direction with higher levels of education being positively associated with the favorable transition from prefrail to non-frail and negatively associated to adverse transitions (Table II). 
TABLE I. PROPORTIONS OF FI STATES AND DEATHS AT EACH WAVE.

\begin{tabular}{|l|l|l|l|l|l|}
\hline & Wave 1 & Wave 2 & Wave 3 & Wave 4 & Wave 5 \\
\hline $\begin{array}{l}\text { Non- } \\
\text { frail }\end{array}$ & $\begin{array}{l}55.5 \% \\
(\mathrm{n}=4540)\end{array}$ & $\begin{array}{l}52.5 \% \\
(\mathrm{n}=3667)\end{array}$ & $\begin{array}{l}50.9 \% \\
(\mathrm{n}=3179)\end{array}$ & $\begin{array}{l}50.1 \% \\
(\mathrm{n}=2794)\end{array}$ & $\begin{array}{l}46.6 \% \\
(\mathrm{n}=2273)\end{array}$ \\
\hline Prefrail & $\begin{array}{l}30.7 \% \\
(\mathrm{n}=2508)\end{array}$ & $\begin{array}{l}32.4 \% \\
(\mathrm{n}=2262)\end{array}$ & $\begin{array}{l}34.3 \% \\
(\mathrm{n}=2140)\end{array}$ & $\begin{array}{l}35.0 \% \\
(\mathrm{n}=1952)\end{array}$ & $\begin{array}{l}36.7 \% \\
(\mathrm{n}=1790)\end{array}$ \\
\hline Frail & $\begin{array}{l}13.8 \% \\
(\mathrm{n}=1126)\end{array}$ & $\begin{array}{l}15.2 \% \\
(\mathrm{n}=1061)\end{array}$ & $\begin{array}{l}14.9 \% \\
(\mathrm{n}=928)\end{array}$ & $\begin{array}{l}14.8 \% \\
(\mathrm{n}=826)\end{array}$ & $\begin{array}{l}16.6 \% \\
(\mathrm{n}=810)\end{array}$ \\
\hline Deaths & $\begin{array}{l}0.0 \% \\
(\mathrm{n}=0)\end{array}$ & $\begin{array}{l}2.5 \% \\
(\mathrm{n}=208)\end{array}$ & $\begin{array}{l}3.8 \% \\
(\mathrm{n}=309)\end{array}$ & $\begin{array}{l}3.2 \% \\
(\mathrm{n}=259)\end{array}$ & $\begin{array}{l}3.4 \% \\
(\mathrm{n}=275)\end{array}$ \\
\hline
\end{tabular}

TABLE II. HAZARD RATIOS AND 95\% CIS OF THE ESTIMATED COVARIATE EFFECTS OF SEX, AGE AND EDUCATION IN THE MULTI-STATE MARKOV MODELS.

\begin{tabular}{|c|c|c|c|c|}
\hline $\begin{array}{c}\text { From - } \\
\text { To }\end{array}$ & Sex (Female) & Age & $\begin{array}{c}\begin{array}{c}\text { Education } \\
\text { (Secondary) }\end{array} \\
\end{array}$ & $\begin{array}{c}\text { Education } \\
\text { (Third/Higher) }\end{array}$ \\
\hline $\begin{array}{c}\text { Frail - } \\
\text { Prefrail }\end{array}$ & $\begin{array}{c}0.84 \\
(0.73,0.97)\end{array}$ & $\begin{array}{c}0.97 \\
(0.96,0.98)\end{array}$ & $\begin{array}{c}1.06 \\
(0.91,1.24)\end{array}$ & $\begin{array}{c}1.09 \\
(0.91,1.30)\end{array}$ \\
\hline $\begin{array}{c}\text { Frail - } \\
\text { Non-frail }\end{array}$ & $\begin{array}{c}0.79 \\
(0.00,482.61)\end{array}$ & $\begin{array}{c}0.94 \\
(0.65,1.35)\end{array}$ & $\begin{array}{c}0.86 \\
(0.00,1250.11) \\
\end{array}$ & $\begin{array}{c}1.43 \\
(0.00,7945.56)\end{array}$ \\
\hline $\begin{array}{l}\text { Frail - } \\
\text { Death }\end{array}$ & $\begin{array}{c}0.61 \\
(0.51,0.73) \\
\end{array}$ & $\begin{array}{c}1.08 \\
(1.07,1.10) \\
\end{array}$ & $\begin{array}{c}0.89 \\
(0.73,1.09) \\
\end{array}$ & $\begin{array}{c}0.93 \\
(0.74,1.17) \\
\end{array}$ \\
\hline $\begin{array}{c}\text { Prefrail - } \\
\text { Frail }\end{array}$ & $\begin{array}{c}1.23( \\
1.09,1.38)\end{array}$ & $\begin{array}{c}1.05 \\
(1.05,1.06)\end{array}$ & $\begin{array}{c}0.86 \\
(0.76,0.98) \\
\end{array}$ & $\begin{array}{c}0.77 \\
(0.67,0.89) \\
\end{array}$ \\
\hline $\begin{array}{l}\text { Prefrail - } \\
\text { Non-frail }\end{array}$ & $\begin{array}{c}0.85 \\
(0.76,0.93) \\
\end{array}$ & $\begin{array}{c}0.97 \\
(0.96,0.97)\end{array}$ & $\begin{array}{c}1.00 \\
(0.88,1.14)\end{array}$ & $\begin{array}{c}1.20 \\
(1.06,1.37)\end{array}$ \\
\hline $\begin{array}{c}\text { Prefrail - } \\
\text { Death }\end{array}$ & $\begin{array}{c}0.63 \\
(0.36,1.09) \\
\end{array}$ & $\begin{array}{c}1.01 \\
(0.97,1.05)\end{array}$ & $\begin{array}{c}0.78 \\
(0.44,1.39) \\
\end{array}$ & $\begin{array}{c}0.48 \\
(0.21,1.08) \\
\end{array}$ \\
\hline $\begin{array}{l}\text { Non-frail } \\
\text { - Frail }\end{array}$ & $\begin{array}{c}1.40 \\
(0.08,25.29) \\
\end{array}$ & $\begin{array}{c}0.82 \\
(0.64,1.05) \\
\end{array}$ & $\begin{array}{c}0.69 \\
(0.03,15.32) \\
\end{array}$ & $\begin{array}{c}0.54 \\
(0.02,14.89) \\
\end{array}$ \\
\hline $\begin{array}{l}\text { Non-frail } \\
\text { - Prefrail }\end{array}$ & $\begin{array}{c}1.19 \\
(1.09,1.30) \\
\end{array}$ & $\begin{array}{c}1.06 \\
(1.05,1.06) \\
\end{array}$ & $\begin{array}{c}0.85 \\
(0.76,0.94) \\
\end{array}$ & $\begin{array}{c}0.79 \\
(0.71,0.89) \\
\end{array}$ \\
\hline $\begin{array}{l}\text { Non-frail } \\
\text { - Death }\end{array}$ & $\begin{array}{c}0.31 \\
(0.09,1.04) \\
\end{array}$ & $\begin{array}{c}1.11 \\
(1.06,1.16)\end{array}$ & $\begin{array}{c}0.65 \\
(0.16,2.61) \\
\end{array}$ & $\begin{array}{c}1.39 \\
(0.45,4.26) \\
\end{array}$ \\
\hline
\end{tabular}

\section{DISCUSSION}

Using data from a large population-based study of ageing spanning an 8-year period, we created an alluvial plot to visualize longitudinal transitions in FI states. Using multistate Markov models, we demonstrated that the probabilities of such transitions are different for different FI states, and that many are affected by age, sex, and education, in the expected directions. Specifically, about sex, our results are in keeping with the known fact that whilst women tend to accumulate more deficits than men of the same age, their risk of mortality tends to be lower [4]. We described a methodology that can help clinicians and the public easily appreciate that transitions in FI states are dynamic and not static as often perceived. Indeed, frailty is not a steady state and progression, but also reversion is common [21].

Our results mirror previous research utilising a multi-state transition model to measure the probability of changes in FI status and in the risk of death [22]. However, alluvial plots to visualise those transitions have not been previously utilized in this context. Our results also agree with previous results that the FI status was reversible among community-dwelling older people, and sociodemographic factors are related to changes in frailty [23].

Our study has limitations. For the mortality outcome, specific causes of death were not studied, and addressing this in future studies could shed further light into the biological risks associated with FI states. In a longitudinal study, the deaths of participants might introduce a selective survival bias, but this was managed by modelling death as a distinct state in the Markov models. However, death is a complex outcome that can be affected by numerous confounding variables including disease burden, physical function, and health behaviours. Therefore, the transition risks reported in our study cannot be considered as causal, as associations may still be subject to potential confounders.

In terms of the statistical approach based on multi-state Markov models, advantages include that they add probabilities to the state transitions seen in the alluvial plot and allow for adjustment for co-variates. However, the models assume that the probabilities from one wave to the next are always the same, which may not be the case in real life. In addition, models censor missing data as missing completely at random, which again, may not reflect the true pattern of missingness. However, the sensitivity analyses considering missing data as an additional state (Appendix III, Table IV) suggested that those who were frailer at a given wave were not more likely to have missing data at future waves $(11 \%$ for all frailty states).

In summary, given the importance of FI states transition information in planning public health interventions, there is a need to support data collection and projects that measure frailty trajectories and transitions between different levels of frailty severity [24], in a way that clinicians and the general public can easily understand. An alluvial visualization complemented by multi-state Markov transition models may be a way to achieve this when dealing with epidemiological big data.

\section{ACKNOWLEDGMENTS}

The authors would like to acknowledge the continued commitment and cooperation of the TILDA participants and research team.

\section{REFERENCES}

[1] D. J. Lowsky, S. J. Olshansky, J. Bhattacharya, and D. P. Goldman, "Heterogeneity in healthy aging," J Gerontol A Biol Sci Med Sci, vol. 69, no. 6, pp. 640-9, Jun 2014, doi: 10.1093/gerona/glt162.

[2] W. Ries and D. Pothig, "Chronological and biological age," Exp Gerontol, vol. 19, no. 3, pp. 211-6, 1984, doi: 10.1016/05315565(84)90041-x.

[3] R. Romero-Ortuno and D. O'Shea, "Fitness and frailty: opposite ends of a challenging continuum! Will the end of age discrimination make frailty assessments an imperative?," Age Ageing, vol. 42, no. 3, pp. 27980, May 2013, doi: 10.1093/ageing/afs 189.

[4] A. B. Mitnitski, A. J. Mogilner, C. MacKnight, and K. Rockwood, "The mortality rate as a function of accumulated deficits in a frailty index," (in eng), Mech Ageing Dev, vol. 123, no. 11, pp. 1457-60, Sep 2002, doi: 10.1016/s0047-6374(02)00082-9.

[5] K. Rockwood and A. Mitnitski, "Frailty defined by deficit accumulation and geriatric medicine defined by frailty," (in eng), Clin Geriatr Med, vol. 27, no. 1, pp. 17-26, Feb 2011, doi: 10.1016/j.cger.2010.08.008.

[6] S. D. Searle, A. Mitnitski, E. A. Gahbauer, T. M. Gill, and K. Rockwood, "A standard procedure for creating a frailty index," $B M C$ Geriatr, vol. 8, p. 24, Sep 30 2008, doi: 10.1186/1471-2318-8-24.

[7] K. Rockwood, A. Mogilner, and A. Mitnitski, "Changes with age in the distribution of a frailty index," Mech Ageing Dev, vol. 125, no. 7, pp. 517-9, Jul 2004, doi: 10.1016/j.mad.2004.05.003.

[8] R. Romero-Ortuno and R. A. Kenny, "The frailty index in Europeans: association with age and mortality," (in eng), Age Ageing, vol. 41, no. 5, pp. 684-9, Sep 2012, doi: 10.1093/ageing/afs051.

[9] D. M. Kanters, L. E. Griffith, D. B. Hogan, J. Richardson, C. Patterson, and P. Raina, "Assessing the measurement properties of a Frailty Index across the age spectrum in the Canadian Longitudinal Study on Aging," J Epidemiol Community Health, vol. 71, no. 8, pp. 794-799, Aug 2017, doi: 10.1136/jech-2016-208853.

[10] E. H. Gordon, N. M. Peel, M. Samanta, O. Theou, S. E. Howlett, and R. E. Hubbard, "Sex differences in frailty: A systematic review and meta-analysis," (in eng), Exp Gerontol, vol. 89, pp. 30-40, Mar 2017, doi: 10.1016/j.exger.2016.12.021.

[11] R. Romero-Ortuno, "Frailty Index in Europeans: association with determinants of health," (in eng), Geriatr Gerontol Int, vol. 14, no. 2, pp. 420-9, Apr 2014, doi: 10.1111/ggi.12122. 
[12] E. Dent, F. C. Martin, H. Bergman, J. Woo, R. Romero-Ortuno, and J. D. Walston, "Management of frailty: opportunities, challenges, and future directions," (in eng), Lancet, vol. 394, no. 10206, pp. 1376-1386, Oct 12 2019, doi: 10.1016/s0140-6736(19)31785-4.

[13] O. A. Donoghue, C. A. McGarrigle, M. Foley, A. Fagan, J. Meaney, and R. A. Kenny, "Cohort Profile Update: The Irish Longitudinal Study on Ageing (TILDA)," Int J Epidemiol, vol. 47, no. 5, pp. 1398-13981, Oct 1 2018, doi: 10.1093/ije/dyy163.

[14] P. M. Kearney et al., "Cohort profile: the Irish Longitudinal Study on Ageing," Int J Epidemiol, vol. 40, no. 4, pp. 877-84, Aug 2011, doi: 10.1093/ije/dyr116.

[15] L. Roe, C. Normand, M. A. Wren, J. Browne, and A. M. O'Halloran, "The impact of frailty on healthcare utilisation in Ireland: evidence from the Irish longitudinal study on ageing," (in eng), BMC Geriatr, vol. 17, no. 1, p. 203, Sep 5 2017, doi: 10.1186/s12877-017-0579-0.

[16] F. G. Pena et al., "Comparison of alternate scoring of variables on the performance of the frailty index," BMC Geriatr, vol. 14, p. 25, Feb 24 2014, doi: 10.1186/1471-2318-14-25.

[17] R. Romero-Ortuno, "An alternative method for Frailty Index cut-off points to define frailty categories," Eur Geriatr Med, vol. 4, no. 5, Nov 1 2013, doi: 10.1016/j.eurger.2013.06.005.

[18] M. Ward et al., "Linking death registration and survey data: Procedures and cohort profile for The Irish Longitudinal Study on Ageing," HRB Open Res, vol. 3, p. 43, 2020, doi: 10.12688/hrbopenres.13083.1.

[19] M. Bojanowski and R. Edwards, "alluvial: R Package for Creating Alluvial Diagrams. $\mathrm{R}$ package version: $0.1-2$, https://github.com/mbojan/alluvial," 2016.

[20] C. Jackson, "Multi-State Models for Panel Data: The msm Package for R. Available online: http://www.jstatsoft.org/v38/i08/," Journal of Statistical Software, vol. 38, 8, pp. 1-29, 2011.

[21] S. Rohrmann, "Epidemiology of Frailty in Older People," Adv Exp Med Biol, vol. 1216, pp. 21-27, 2020, doi: 10.1007/978-3-030-33330-0_3.

[22] N. Fallah, A. Mitnitski, S. D. Searle, E. A. Gahbauer, T. M. Gill, and K. Rockwood, "Transitions in frailty status in older adults in relation to mobility: a multistate modeling approach employing a deficit count," $J$ Am Geriatr Soc, vol. 59, no. 3, pp. 524-9, Mar 2011, doi: 10.1111/j.1532-5415.2011.03300.x.

[23] B. Ye et al., "Changes in frailty among community-dwelling Chinese older adults and its predictors: evidence from a two-year longitudinal study," BMC Geriatr, vol. 20, no. 1, p. 130, Apr 10 2020, doi: 10.1186/s12877-020-01530-x.

[24] R. O'Caoimh et al., "Transitions and trajectories in frailty states over time: a systematic review of the European Joint Action ADVANTAGE," Ann Ist Super Sanita, vol. 54, no. 3, pp. 246-252, JulSep 2018, doi: 10.4415/ANN_18_03_12.

\section{APPENDIX I}

The 31 componants of the FI: diffuculty walking 100 meters; difficulty rising from a chair; difficulty climbing one flight of stairs; difficulty stooping; kneeling or crouching; difficulty reaching above shoulder height; difficulty pushing/pulling large objects; difficulty lifting/carrying weights $>=10 \mathrm{lb}$ ( $4.5 \mathrm{~kg})$; difficulty picking up coin from table; feeling lonely; poor self rated physical health; poor self rated vision; poor self rated hearing; difficulty following a conversation with one person; daytime sleepiness; polypharmacy; knee pain; hypertension; angina; heart attack; diabetes; high cholesterol; irregular heart rhythm; other cardiovascular disease; cataracts, arthritis; osteoporosis; cancer; varicose ulcer; stroke/transient ischemic attack; glaucoma/age related macular degeneration; self rated dayto-day memory.

\section{APPENDIX II}

TABLE III. NUMBERS OF TRANSITIONS FOR FRAILTY INDEX STATES.

\begin{tabular}{|l|l|l|l|l|l|}
\hline \multicolumn{4}{|l|}{ TO } \\
\hline FROM & Frail & Pre-frail & Non-frail & Death & Missing \\
\hline Frail & 2144 & 891 & 47 & 390 & 469 \\
\hline Pre-frail & 1205 & 4760 & 1649 & 307 & 941 \\
\hline Non-frail & 172 & 2329 & 10000 & 158 & 1521 \\
\hline Death & 0 & 0 & 0 & 1499 & 0 \\
\hline Missing & 104 & 164 & 217 & 185 & 3544 \\
\hline
\end{tabular}

\section{APPENDIX III}

TABLE IV. SENSITIVITY ANALYSIS WHERE MISSING DATA WAS CONSIDERED AS AN ADDITIONAL STATE IN THE MULTI-STATE MARKOV MODELS. ESTIMATED TRANSITION PROBABILITIES (AND 95\% CIS) FOR EACH FRAILTY INDEX STATE (FROM WAVE X TO WAVE X + 1) ARE SHOWN.

\begin{tabular}{|l|l|l|l|l|l|}
\hline \multicolumn{5}{|l|}{ TO } & \multicolumn{5}{l|}{} \\
\hline FROM & Frail & Pre-frail & Non-frail & Death & Missing \\
& & & & & \\
\hline Frail & 0.55 & 0.19 & 0.03 & 0.12 & 0.11 \\
& $(0.53$, & $(0.18$, & $(0.03$, & $(0.11$, & $(0.10$, \\
& $0.56)$ & $0.20)$ & $0.04)$ & $0.13)$ & $0.12)$ \\
\hline Pre-frail & 0.14 & 0.55 & 0.18 & 0.02 & 0.11 \\
& $(0.14$, & $(0.52$, & $(0.17$, & $(0.02$, & $(0.10$, \\
& $0.15)$ & $0.56)$ & $0.18)$ & $0.06)$ & $0.12)$ \\
\hline Non-frail & 0.02 & 0.16 & 0.71 & 0.01 & 0.11 \\
& $(0.02$, & $(0.15$, & $(0.70$, & $(0.01$, & $(0.11$, \\
& $0.02)$ & $0.16)$ & $0.71)$ & $0.01)$ & $0.12)$ \\
\hline Death & 0.00 & 0.00 & 0.00 & 1.00 & 0.00 \\
& $(0.00$, & $(0.00$, & $(0.00$, & $(1.00$, & $(0.00$, \\
& $0.00)$ & $0.00)$ & $0.00)$ & $1.00)$ & $0.00)$ \\
\hline Missing & 0.01 & 0.06 & 0.05 & 0.07 & 0.82 \\
& $(0.01$, & $(0.05$, & $(0.04$, & $(0.06$, & $(0.81$, \\
& $0.01)$ & $0.06)$ & $0.05)$ & $0.08)$ & $0.83)$ \\
\hline
\end{tabular}

